\title{
Deferencia a la soberanía nacional. Práctica y doctrina del margen de apreciación nacional en el Sistema Interamericano de Derechos Humanos*
}

\section{National Sovereignty Deference. National Margin of Appreciation Doctrine and Practice in the Inter-American Human Rights System}

\author{
Deference de la souveraineté. \\ La pratique et la doctrine de la marge \\ d'appréciation dans le système interaméricain \\ de protection des droits de l'homme
}

\section{Édgar Hernán Fuentes Contreras ${ }^{* *}$ Luz Eliyer Cárdenas Contreras ${ }^{* * *}$}

\begin{abstract}
SUMARIO: I. Introducción. II. Construcción conceptual del margen de apreciación. III. Recolección de la jurisprudencia sobre el margen. IV. Desarrollo interamericano del margen de apreciación. V. Observaciones frente a los parámetros de aplicabilidad del margen. VI. Conclusiones. VII. Bibliografía.
\end{abstract}

* Artículo de investigación que expone los resultados preliminares de los proyectos de posdoctorado y doctorado de los autores, respectivamente, financiados por la Universidad de los Andes, Chile, a través del Fondo de Ayuda a la Investigación.

** Universidad de los Andes, Chile; ORCID ID: https: / / orcid.org/0000-0002-1066-0999.

*** Universidad de los Andes, Chile; ORCID ID: https://orcid.org/0000-0001-7986-4343, lecardenas@miuandes.cl.

Artículo recibido el 10 de junio de 2020

Aprobado para publicación el 9 de octubre de 2020 
RESUMEN: Con dificultad puede sostenerse, hoy en día, que la inclusión de la doctrina del margen de apreciación nacional es un asunto exclusivo del sistema europeo de protección de los derechos humanos. Por el contrario, su uso directo o indirecto en el Sistema Interamericano de Derechos Humanos abre un espacio de discusión sobre su comprensión y desarrollo que va más allá de la simple mención de la categoría. En ese sentido, se busca examinar los parámetros de aplicabilidad del margen de apreciación nacional dentro del contexto de este sistema regional de protección, entre los años 1981-2020. Para ello, se compondrá de cuatro acápites, iniciando por el marco conceptual, para pasar a la metodología y sus respectivos resultados y finalizar, previo a las conclusiones, con las observaciones de comprensión de esta categoría.

Palabras clave: Sistema Interamericano, deferencia, margen de apreciación, soberanía, derechos humanos.

ABSTRACT: Nowadays, it is difficult to argue that the inclusion of the doctrine national margin of appreciation is an exclusive matter of the European System of Human Rights Protection. On the contrary, the direct or indirect use of this doctrine by the Inter-American Human Rights System opens a space for discussion about its understanding and development, going beyond the conceptual mention of this category. In this sense, this article seeks to examine, from an exploratory methodology, the application parameters of the national margin of appreciation within the context of the latter regional protection system, between 1981-2020. To do this exercise, this article has four sections. It starting with a conceptual framework in order to move on to the methodology section and its respective results. The article ends prior to the conclusions, with the understanding observations of the margin of national appreciation category.

Key words: Inter-American Human Rights System, deference, margin of appreciation, sovereignty, human rights.

RÉSUMÉ: De nous jours, on ne peut qu'affirmer que l'inclusion de la doctrine de la marge d'appréciation nationale n'est plus une question exclusive du système européen de protection des droits de l'homme. Au contraire, son utilisation directe ou indirecte dans le Système interaméricain des droits de l'homme ouvre un espace de discussion sur sa compréhension et son développement, qui va au-delà de la simple mention conceptuelle de la catégorie. Quatre sections composent cet article qui poursuit, à partir d'une étude exploratoire, l'objectif général d'identifier et examiner les paramètres d'applicabilité de la marge d'appréciation nationale dans le cadre de ce système régional de protection des droits de l'homme, entre les années 1981-2020. Pour ce faire, tout d'abord on commencera par présenter le cadre conceptuel, afin de pouvoir examiner la méthodologie et ces résultats respectifs et, avant les conclusions, analyser les observations de compréhension de cette catégorie.

Mots-clés: Système Interaméricain, déférence, marge d'appréciation, souveraineté, droits humains. 


\section{INTRODUCCIÓN}

Tal como es conocido, el desarrollo y uso de la doctrina del margen de apreciación nacional (en adelante margen de apreciación) se ha encontrado en el Tribunal Europeo de Derechos Humanos (TEDH), el cual ha reconocido una libertad configurativa de los Estados para interpretar ciertas obligaciones del Convenio Europeo para la Protección de los Derechos Humanos y de las Libertades Fundamentales (en adelante CEDH).

Precisamente, será en el TEDH, tomando como referencia la Comisión Europea de Derechos Humanos, quien permitirá observar el margen de apreciación como una herramienta que limita el control judicial de los tribunales internacionales, en razón al reconocimiento del ejercicio de la autonomía poder estatal "en torno a la determinación (contenido y alcance) de los derechos humanos". ${ }^{1}$

Pese a que dicha doctrina no puede ser considerada como reciente en su formación, ${ }^{2}$ debido a que su primer uso en el sistema europeo fue en 1958, en el sistema regional interamericano de protección de derechos humanos (en adelante Sistema Interamericano o Sistema Interamericano de Derechos Humanos) su uso ha sido sometido a percepciones discordes, al punto de ser negada su existencia en el quehacer de la Corte Interamericana de Derechos Humanos (en adelante Corte o CoIDH). ${ }^{3}$

1 Acosta Alvarado, Paola Andrea, "Los casos colombianos ante el sistema interamericano y el uso del margen de apreciación: ¿ausencia justificada?", en Núñez Poblete, Manuel y Acosta Alvarado, Paola Andrea (coords.), El margen de apreciación en el Sistema Interamericano de Derechos Humanos: proyecciones regionales y nacionales, México, UNAM, 2012, pp. 183.

2 "Los primeros antecedentes de este concepto se remontan a la actuación de la Comisión Europea de Derechos Humanos en los asuntos Grecia c. Reino Unido [1958], Lawless c. Irlanda [1959], y Dinamarca, Noruega, Suecia y Países Bajos c. Grecia [1969]”. López Alfonsín, Marcelo Alberto, "La doctrina del margen de apreciación nacional. Su recepción en el Sistema Europeo de Derechos Humanos, en el Sistema Interamericano de Derechos Humanos y en Argentina, en relación con los derechos económicos, sociales y culturales”, Lex, año XV, núm. 19, enero-junio de 2017, p. 56.

3 “...la figura del margen de apreciación en su concepción más estricta no ha sido recepcionada por la Corte Interamericana de Derechos Humanos, lo cual tiene fundamentos normativos y se basa en el principio de efectividad en la protección”. Nash Rojas, Claudio, "La doctrina del margen de apreciación y su nula recepción en la jurisprudencia de la Corte 
Con todo, más allá de las posiciones que permite considerar la conveniencia y oportunidad de la categoría en referencia, ${ }^{4}$ un ámbito notorio sobre el estudio de la recepción de una idea, categoría o teoría jurídica es que éste no puede basarse de manera exclusiva en el uso del término o expresión. Si así fuera se podría afirmar, por ejemplo, que la recepción o trasplante del bloque de constitucionalidad de origen francés por parte de los países latinoamericanos es totalmente errado y no equivalente a la formulación original. ${ }^{5}$ De tal modo, bajo la hipótesis de que existe una inclusión de la categoría, seguramente sometida a una mutación o a una lectura trasformadora, ${ }^{6}$ en la jurisprudencia del Sistema Interamericano, el presente artículo dará respuesta a la siguiente pregunta de investigación: ¿cuál es el parámetro de aplicabilidad del margen de apreciación dentro del contexto del Sistema Interamericano de Derechos Humanos entre 1981-2020?

Para dar respuesta a dicha indagación se diseñó un estudio exploratorio de los casos contenciosos de la Comisión Interamericana de Derechos $\mathrm{Hu}$ manos (en adelante Comisión o CIDH) y de las sentencias la Corte, con el fin de elaborar una presentación correlacional basada en cuatro acápites previos a las conclusiones: el primero, que funciona como marco conceptual, indaga los elementos de la noción del margen de apreciación, para

Interamericana de Derechos Humanos”, ACDI, vol. 11, 2008, p. 96; cfr. Lovatón Palacios, David, “¿Debería incorporarse en el Sistema Interamericano de Derechos Humanos la noción de margen de apreciación nacional?”, Estudios Constitucionales, año 16, núm. 2, juliodiciembre de 2018, pp. 339-368.

4 "Su existencia se encuentra justificada por la ausencia de un consenso entre los diferentes Estados parte dentro de los tratados, lo que hace que los tribunales regionales se encuentren impedidos para la posible construcción de una regla de interpretación unificada”. Barbosa Delgado, Francisco R., "Los límites a la doctrina del margen nacional de apreciación en el Tribunal Europeo y la Corte Interamericana de Derechos Humanos: intervención judicial en torno a ciertos derechos de las minorías étnicas y culturales", Derecho del Estado, núm. 26, enero-junio de 2011, p. 110; cfr. Barbosa Delgado, Francisco R., "El margen nacional de apreciación en el derecho internacional de los derechos humanos: entre el Estado de derecho y la sociedad democrática”, en Núñez Poblete, Manuel y Acosta Alvarado, Paola Andrea (coords.), op. cit., pp. 51-82.

5 Cfr. Astudillo, César, El bloque y el parámetro de constitucionalidad en México, México, Tirant lo Blanch, 2014; Maldonado Sánchez, Adán, El bloque de constitucionalidad en México. Hacia su integración y aplicación, México, Tirant lo Blanch, 2019; Fuentes-Contreras, Édgar Hernán, Materialidad de la Constitución, Bogotá, Grupo Editorial Ibáñez y otro, 2010.

6 Cfr. López Medina, Diego Eduardo, Teoría impura del derecho, Bogotá, Universidad de los Andes y otros, 2004. 
pasar, en un segundo momento, a la descripción de la metodología de recolección empleada, y como tercer acápite, a una recapitulación correlacional temática del tratamiento del margen de apreciación en el Sistema Interamericano; finalmente, se desarrollan las observaciones correspondientes a los parámetros de aplicabilidad.

\section{CONSTRUCCIÓN CONCEPTUAL DEL MARGEN DE APRECIACIÓN}

El origen del margen de apreciación nacional suele vincularse como un reflejo parcial de nociones internas, ${ }^{7}$ tales como las empleadas en el Consejo de Estado francés al desarrollar el marge d'appréciation, ${ }^{8}$ el ermessensspielraum de la doctrina alemana, ${ }^{9}$ o los llamados conceptos indeterminados del derecho administrativo. ${ }^{10}$ Empero, dichas nociones distan realmente del uso que se le atribuyó al margen de apreciación aplicado por la Comisión Europea de Derechos Humanos, quien la empleó por vez primera en el caso Grecia vs. Reino Unido, 1958-1959 ${ }^{11}$, y de manera posterior elTEDH. ${ }^{12}$

Ambos órganos se ampararon en el artículo 15 del CEDH, que permitía derogar de manera temporal las obligaciones del Convenio en casos de guerra o de peligros públicos que amenazaran la vida de la nación, en la estricta medida en que lo exigiera la situación. A partir de ello empezaron a construir esta categoría y, con posterioridad, la hicieron extensiva, desde

7 Véase Martínez Estay, José Ignacio, “Auto-restricción, deferencia y margen de apreciación. Breve análisis de sus orígenes y de su desarrollo”, Estudios Constitucionales, año 12, núm. 1, julio-diciembre de 2014, pp. 365-396.

8 Marochini, Maša, "The Interpretation of the European Convention on Human Rights", Bornik Radova Pravnog Fakulteta u Splitu, vol. 51, núm. 1, enero-junio de 2014, p. 69.

9 Cfr. Sommermann, Karl-Peter, "El papel de la ley alemana de la justicia administrativa para la realización del Estado de derecho", en Aberasturi, Pedro (coord.), Ley de la justicia administrativa alemana, Buenos Aires, Konrad Adenauer-Abeledo Perrot, 2009, pp. 1-20.

10 Cfr. García de Enterría, Eduardo, "La lucha contra las inmunidades del poder en el derecho administrativo (poderes discrecionales, poderes de gobierno, poderes normativos)", Revista de Administración Pública, núm. 38, mayo-agosto de 1962, pp. 159-208.

11 Greer, Steven, The Margin of Appreciation: Interpretation and Discretion under the European Convention on Human Rights, Strasbourg, Council of Europe, 2000, pp. 40 y 41.

12 Cfr. Arai-Takahashi, Yutaka, The Margin of Appreciation Doctrine and the Principle of Proportionality in the Jurisprudence of the ECHR, Antwerp, Intersentia, 2002. 
elTEDH, para otras obligaciones contenidas en el Convenio y el Protocolo I Adicional, ${ }^{13}$ con lo cual ha llevado a aludirse, inclusive, en un uso inflacionario de esta doctrina. ${ }^{14}$

Así, a pesar de que "La doctrina del margen no está incluida de forma expresa entre los preceptos del Convenio Europeo ni tampoco fue mencionada ni debatida en los trabajos preparatorios", ${ }^{15}$ se puede observar como una garantía del principio de subsidiaridad, "que es inherente a una protección internacional y debe lógicamente producirse después de la interna y en defecto de la misma. La justificación de esta doctrina procede de la misma naturaleza de una tutela internacional". ${ }^{16}$

Pese a su utilización frecuente y a su reciente positivización, el TEDH no ha definido de manera unívoca el concepto y las características de esta figura. En los casos en que la ha aplicado, el TEDH no ha hecho un esfuerzo argumentativo fuerte para explicar con profundidad sus presupuestos, sino que se ha limitado a utilizarla. El vacío teórico ha sido suplido por algunos autores que han podido deducir que el margen nacional de apreciación es una figura mediante la cual el TEDH se inhibe de conocer un asunto y determinar si el contenido de los derechos en disputa ha sido vulnerado. ${ }^{17}$

La abstinencia del Tribunal en el juzgamiento de los Estados solía estar conectada con la ausencia de uniformidad sobre la regulación del derecho al interior de los Estados, que se asumía como la carencia de un consenso internacional:

13 Sánchez-Molina, Pablo, "El margen de apreciación nacional en las sentencias del Tribunal Europeo de Derechos Humanos relativas al derecho a elecciones libres”, Estudios de Deusto, vol. 62, núm. 1, enero-junio de 2014, pp. 371-386.

${ }^{14}$ Cfr. Kratochvíl, Jan, "The Inflation of the Margin of Appreciation by the European Court of Human Rights", Netherlands Quarterly of Human Rights, vol. 29, núm. 3, septiembre-noviembre de 2011, pp. 324-357.

15 García Roca, Javier, "La muy discrecional doctrina del margen de apreciación nacional según el Tribunal Europeo de Derechos Humanos: soberanía e integración”, Teoría y Realidad Constitucional, núm. 20, julio-diciembre de 2007, p. 121.

16 Idem. Véase, además, D’Alterio, Elisa, La funzione di regolazione delle Corti Nello Spaio Ammnistrativo Globale, Milano, Giuffrè, 2011.

17 Fernández Parra, Sergio Alejandro, "El margen nacional de apreciación y el contenido de la libertad de pensamiento, conciencia y religión en el Convenio Europeo de Derechos Humanos”, Eunomía, núm. 17, octubre de 2019-marzo de 2020, p. 80. 
La aplicación del consenso como criterio interpretativo obedece a razones evidentes. Es la comunidad regida por las normas convencionales a aplicar la que le da vida a esas normas. Es la comunidad la que vive el derecho y determina su contenido preciso partiendo de un núcleo inderogable. La sociedad evoluciona, lo que se manifiesta, entre otros, en actos legislativos, ejecutivos y judiciales. Pero cuando el tribunal no ha encontrado un consenso en torno al sentido y alcance del derecho, en ocasiones se ha aplicado lo que se conoce como el margen de apreciación. ${ }^{18}$

De este modo, no parece erróneo asumir a "La dottrina del margine di apprezzamento indica, infatti, lo spazio lasciato agli Stati nell'applicazione della Convenzione per bilanciare l'adempimento degli obblighi pattizi con la tutela di altre esigenze statali". ${ }^{19}$ En otras palabras, un "espacio de maniobra", "the breadth of deference" o, simplemente, el grado de deferencia que los órganos internacionales reconocen a los de los Estados parte en el cumplimiento de las obligaciones internacionales. ${ }^{20}$

En esa dirección, no sólo son múltiples los casos, sino también las temáticas en las cuales se ha empleado esta doctrina en el sistema europeo, ${ }^{21}$ lo

18 Benavides Casals, María Angélica, "El ConsensoY El Margen De Apreciación En La Protección De Los Derechos”, Ius Et Praxis, vol. 15, núm. 1, enero-junio de 2009, pp. 300 y 301.

19 Anrò, Ilaria, Il margine di apprezzamento nella giurisprudenza della Corte di giustizia dell'Unione europea e della Corte europea dei Diritti dell'uomo, Nápoles, Edizioni Scientifiche Italiane, 2010, pp. 9 y 10.

20 Sánchez Molina, Pablo, "Margen de apreciación nacional (en los sistemas de protección internacional de los derechos humanos)”, Eunomía, núm. 9, octubre de 2015-marzo de 2016, p. 226. Cfr. "Most of the definitions of the doctrine concentrate on the deference that the doctrine provides to States. Yourow describes it as «freedom to act; manoeuvring, breathing or «elbow» room; or the latitude of deference or error which the Strasbourg organs will allow to national legislative, executive, administrative and judicial bodies before it is prepared to declare» a violation of the Convention. Arai-Takahashi talks about a «latitude a government enjoys» in applying the provisions of a treaty. Benvenisti similarly described it as a «certain latitude [each society has] in resolving the inherent conflicts between individual rights and national interests or among different moral convictions». Greer refers to a «room for manoeuvre the Strasburg institutions are prepared to accord national authorities in fulfilling their obligations» and «bandwidth». Merrills talks about an «area of discretion»”. Kratochvíl, Jan, op. cit., p. 327.

21 Verbigracia, sobre la prohibición de tortura, tratos crueles y degradantes el caso Tyrer vs. Reino Unido (1978); frente al derecho al respeto a la vida privada y familiar el caso Goodwin vs. Reino Unido (2002), Pretty vs. Reino Unido (2002), Sheffield y Horsham vs. Reino Unido 
que ha facilitado el carácter multívoco de la doctrina y, de igual manera, que se pueda aludir a grados de deferencia dependiendo del asunto. ${ }^{22}$

En esa perspectiva, la amplitud del concepto no fue un impedimento, sino que, por el contrario, sirvió para que el margen de apreciación se abriera sitio en el Sistema Interamericano de Derechos Humanos, que contaba con circunstancias análogas, aunque no idénticas a su sitio de origen. ${ }^{23}$ De allí, como elemento objeto de trasplante jurídico, ${ }^{24}$ su estudio debe desarrollarse, especialmente, como un fenómeno contextual, y para eso se acudirá a la metodología que será presentada.

\section{RECOLECCIÓN DE LA JURISPRUDENCIA}

SOBRE EL MARGEN

Si se entiende, como se ha presentado, el margen de apreciación como una
"doctrina transregional del derecho de los derechos humanos, en la medida

(1998), Rees vs. Reino Unido (1986); en relación con la libertad de expresión el caso Handyside vs. Reino Unido (1976), Sunday Times vs. Reino Unido (1979); en materia de recursos efectivos, Vilvarajah vs. Reino Unido (1991), Chahal vs. Reino Unido (1996); frente a la prohibición de discriminación Frette vs. Francia (2002), Pretty vs. Reino Unido (2002), D. H. y otros vs. República Checa (2006), Evans vs. Reino Unido (2007), Thlimmenos vs. Grecia (2000).

22 Cfr. García Roca, Javier, El margen de apreciación nacional en la interpretación del Convenio Europeo de Derechos Humanos: soberanía e integración, Madrid, Civitas, 2010.

23 Cfr. Sánchez Molina, Pablo, "Margen de apreciación nacional...”, cit., p. 227. "Con razón se pregunta si, frente a estas circunstancias, sería razonable «importar» una noción que sigue siendo ambigua, difícil de aplicar en la práctica, y «muy alejada del contexto sociológico interamericano»". Clérico, Laura, "La enunciación del margen de apreciación: Fontevecchia 2017 desde los márgenes”, Derechos en Acción, año, 3, vol. 7, núm. 7, otoño de 2018, p. 312. En sentido similar: Clérico, Laura y Aldao, Martín, "Límites al margen de apreciación desde la perspectiva de género en intersección con pobreza”, Centro de Estudios Constitucionales, año IV, núm. 6, enero-junio de 2018, pp. 121-157.

24 Entre otros, ver, por ejemplo: Watson, Alan, Legal Transplants: An Approach to Comparative Law, Atenas y Londres, The University of Georgia Press, 1993; Backenköhler Casajús, Christian J., "Transplante jurídico=Legal Trasplant”, Eunomía, núm. 17, octubre de 2019-marzo de 2020, pp. 262-275; Bonilla Maldonado, Daniel (ed.), Teoría del derecho y trasplantes jurídicos, Bogotá, Siglo del Hombre y otros, 2009; Rodríguez Villabona, Andrés Abel, "La interacción entre ordenamientos jurídicos: trasplante, recepción, adaptación e influencia en el derecho", IUSTA, núm. 31, julio-diciembre de 2009, pp. 99-122. 
Esta revista forma parte del acervo de la Biblioteca Jurídica Virtual del Instituto de Investigaciones Jurídicas de la UNAM

en que su origen está en el derecho europeo y su sitio de recepción es el SIDH". ${ }^{25}$ La identificación del empleo de dicha categoría puede implicar, por un lado, el uso literal de la expresión y, por el otro, su reconocimiento, más allá del término, por la finalidad o propósito de la noción. De tal modo, se construye una metodología de recolección de información jurisprudencial designada como método de sinonimia analógica o correlacional. ${ }^{26}$

La construcción de este método siguió, como paso inicial, un abordaje doctrinal y jurisprudencial con el fin de detectar vocablos o locuciones que pudieran hacer alusión mediata a la categoría "margen de apreciación” en el contexto europeo. Gracias a dicha valoración se produjo un listado de voces que sustentarían cierta similitud o podían llevar a establecer el uso de la categoría objeto de estudio, así:

\section{TABLA 1. VOCABLOS CORRELACIONADOS PARA LA IDENTIFICACIÓN DE LA CATEGORÍA "MARGEN DE APRECIACIÓN NACIONAL"}

\begin{tabular}{|c|l|l|}
\hline \multicolumn{3}{|c|}{ Margen de apreciación nacional } \\
\hline \multirow{2}{*}{ Sistema Europeo } & \multicolumn{2}{|c|}{ Sistema Interamericano } \\
\hline \multirow{4}{*}{$\begin{array}{c}\text { Margen/margin } \\
\text { deferencia/deference }\end{array}$} & Margen & Subsidiariedad \\
\cline { 2 - 3 } & Deferencia & Reserva \\
\cline { 2 - 3 } & Límite & Soberanía \\
\cline { 2 - 3 } & Discrecionalidad & Sesgo \\
\cline { 2 - 3 } & Potestad & Capacidad de apreciación \\
\cline { 2 - 3 } & Consenso & \\
\hline
\end{tabular}

Bajo aspectos de identidad o equivalencia, dichas expresiones sirvieron para examinar las sentencias del TEDH, la CoIDH y la CIDH, y, en uso de ellas, establecer alusiones directas o indirectas a la categoría. Si bien en

25 Cárdenas-Contreras, Luz Eliyer, La evolución del margen de apreciación nacional en el Sistema Interamericano de Derechos Humanos como doctrina transregional, tesis de maestría en Derecho de Estado con énfasis en derecho público, Bogotá, Universidad Externado de Colombia, 2019.

26 Dicho procedimiento se sustenta en el método censitario, expuesto, por ejemplo, en Fuentes-Contreras, Édgar Hernán et al., "Facticidad y acción de tutela: presentación preliminar de un estudio empírico de la formulación y efectos de la acción de tutela en el marco colombiano, entre los años 1992-2011”, Civilizar, vol. 14, núm. 27, julio-diciembre de 2014, pp. 41-64. 
la revisión se detectaron un total de 28 sentencias del TEDH, se optó, en concordancia con el objetivo del artículo, dar prevalencia al tratamiento dado por los órganos que conforman el Sistema Interamericano de Derechos Humanos. Para tal fin, se organizaron las decisiones contenidas en las plataformas oficiales de la Corte y de la Comisión ${ }^{27}$ entre 1988 y 1981, respetivamente, y hasta 2020, además de que se realizó la exploración de las mismas a través de los vocablos propuestos. Como resultado del rastreo se registraron 18 temáticas:

\section{TABLA 2. IDENTIFICACIÓN TEMÁTICA PARA EFECTO DE LA CONSTRUCCIÓN DEL CONCEPTO DE "MARGEN DE APRECIACIÓN NACIONAL" EN EL Sistema INTERAMERICANO DE DERECHOS Humanos}

\begin{tabular}{|l|l|l|}
\hline \multicolumn{2}{|c|}{ Temáticas } \\
\hline \multicolumn{1}{|c|}{ CIDH } & \multicolumn{1}{|c|}{ Ambos órganos } & \multicolumn{1}{c|}{ CoIDH } \\
\hline $\begin{array}{l}\text { 1) Colegiatura profesio- } \\
\text { nal obligatoria }\end{array}$ & $\begin{array}{l}\text { 1) Protección de la vida } \\
\text { desde la concepción }\end{array}$ & $\begin{array}{l}\text { 1) Reserva procesal } \\
\text { 2) Declaratorias de esta- } \\
\text { do de emergencián }\end{array}$ \\
2) Derechos políticos & 2) Derechos económi- \\
3) Derecho a la naciona- & 3) Detenciones arbitra- \\
rias & $\begin{array}{l}\text { cos, sociales y culturales } \\
\text { lidad }\end{array}$ & 3) Idoneidad y eficacia \\
4) Inmigración irregular & 4) Pena de muerte recursos judiciales \\
5) Derechos reproduc- & 5) Ejercicio de la liber- & 4) Propiedad colectiva \\
tivos & tad de expresión y pen- & de las comunidades in- \\
6) Servicio militar obli- & samiento & dígenas \\
gatorio & & 5) Amnistías e indultos \\
7) Juicios políticos & & \\
8) Reserva procesal & & \\
como garantía & & \\
\hline
\end{tabular}

No obstante, debe aclararse que la identificación temática realizada no implica per se que se reconozca el uso pleno del margen de apreciación esta-

27 En el caso de la Corte se ingresó al acápite de jurisprudencia-casos contenciosos (http: / / www.corteidh.or.cr/cf/Jurisprudencia2 / busqueda_casos_contenciosos.cfm?lang=es), mientras para la Comisión se ingresa mediante el espacio casos-informes y, finalmente, informes de fondo (http://www.oas.org/es/cidh/decisiones/fondos.asp). La fecha de búsqueda fue el 3 de junio de 2020. 
tal. Tal como será expuesto a continuación, se detectaron las categorías de deferencia amplia, moderada, leve y nula, según el asunto.

\section{DESARROLLO INTERAMERICANO}

DEL MARGEN DE APRECIACIÓN

Una primera aparición del concepto de margen de apreciación se dio en el caso conocido por la Comisión como Baby Boy vs. Estados Unidos (1981), el cual recurrió a la idea de consenso para discutir la vulneración del derecho a la vida que yace en la Declaración Americana de los Derechos y Deberes del Hombre (en adelante Declaración Americana) y en el artículo 4o. de la Convención Americana sobre Derechos Humanos (CADH).

Tras recurrir a elementos históricos y al proyecto de la $\mathrm{CADH}$, la Comisión concluyó que ante la ausencia de un consenso fue que se incluyó la expresión "en general" en el artículo 4.1 de la CADH, lo que cuenta con implicaciones normativas. En consecuencia, consideró que la decisión tomada por la jurisdicción de Estados Unidos no era contraria al corpus iuris interamericano y, por demás, reconoce el margen de apreciación del Estado para definir las situaciones excepcionales que impiden la protección desde el momento de la concepción.

Con relación a este mismo derecho, la CoIDH usó término análogo al margen de apreciación para tratar la pena de muerte en el caso DaCosta Dogon vs. Barbados (2009). En su análisis, la Corte manifestó que, desde la CADH, no existe una prohibición expresa y total de dicha pena, sino que deja, con cierta discrecionalidad, la decisión a los Estados, siempre que se respeten las restricciones del artículo 4o. convencional, tal como ya se había sostenido en la Opinión Consultiva 03/83. Sin embargo, la Corte agregó en el caso contra Barbados (2009) que dichas restricciones deben ser interpretadas, además, bajo el principio pro persona, pues "dichas disposiciones imponen restricciones para limitar rigurosamente la aplicación y alcance de la pena de muerte, de muerte que se vaya reduciendo hasta la supresión final" (párr. 49). Interpretación que provocaría que el margen de apreciación en la materia, incluso frente a regulaciones preconvencionales, sea moderado pero gradual hasta su desaparición. 
En 2017 el tema fue retomado, sólo que ahora por parte de la CIDH, que declara que la pena de muerte no es violatoria per se a la Declaración Americana. ${ }^{28}$ Por tanto, llevó su estudio del caso Víctor Saldaño vs. Estados Unidos al "estándar de apreciación de las alegadas violaciones de derechos humanos en el marco de un proceso que culmina con pena de muerte" (párr. 173). En esa oportunidad la Comisión dijo que, puesto que Estados Unidos no ha reconocido la competencia de la Corte Interamericana y tampoco a la Convención, se debían interpretar normas disimiles a los casos conocidos por la Corte. De cualquier manera, la CIDH advirtió la importancia de que las normas, procedimientos y prácticas relacionados con la pena de muerte sean acordes a las disposiciones de la Declaración Americana; por ejemplo, las que se incluyen en los artículos I, II, XVIII, XV y XXVI. Por consiguiente, destacando la rigurosidad de las garantías judiciales.

Dicha doctrina coincide con la afirmada, referente a las detenciones arbitrarias. Precisamente, la CIDH, en 2016, asumió el caso Manickavasagam Suresh vs. Canadá, de un refugiado detenido por haber sido un miembro de Liberation Tamil Tigers Eelam y acusado de cometer actos terroristas en su país de origen. Al final la Comisión halló responsable a Canadá por vulneraciones a las garantías judiciales, en especial por el arresto arbitrario y la negación de medios adecuados y oportunos para impugnar la legalidad de la detención, incluido el derecho de habeas corpus y la igualdad ante la ley (párr. 5). Puntualmente, se dispuso "que los fundamentos y procedimientos conforme a los cuales se puede privar de la libertad a no ciudadanos deben definir con suficiente detalle el fundamento de esa acción, que las autoridades deben disponer de un margen muy reducido y limitado de discrecionalidad" (párr. 72), dando cierre a espacios de aplicación que se compaginaron con aquello que la Corte expresó; por ejemplo, en el caso Chaparro y Lapo vs. Ecuador (2007), donde, sobre la libertad personal, la CoIDH indicó:

Ahora bien, este derecho puede ejercerse de múltiples formas, y lo que la Convención Americana regula son los límites o restricciones que el Estado puede realizar. Es así como se explica que el artículo 7.1 consagre en términos generales el derecho a la libertad y seguridad y los demás numerales se encarguen de las diversas garantías que deben darse a la hora de privar a alguien de su libertad. De ahí también se

28 Cfr. caso Peter Cash vs. Commonwealth de las Bahamas, Informe de Fondo No. 12/14; caso Edgar Tamayo Arias, Informe de Fondo No. 44/14. 
explica que la forma en que la legislación interna afecta al derecho a la libertad es característicamente negativa, cuando permite que se prive o restrinja la libertad. Siendo, por ello, la libertad siempre la regla y la limitación o restricción siempre la excepción (párr. 53).

De esta suerte, las restricciones a este derecho no sólo son excepcionales, sino consentidas al estar en el instrumento; de manera que la discrecionalidad se sujeta a la legalidad y proporcionalidad de la decisión.

Por otra parte, frente a las garantías judiciales estará la sentencia del caso Herrera Ulloa vs. Costa Rica (2004), donde se discutió, para el tema objeto de estudio, el artículo 8.2.h de la CADH. Al resolver la controversia, la Corte afirma:

Si bien los Estados tienen un margen de apreciación para regular el ejercicio de ese recurso, no pueden establecer restricciones o requisitos que infrinjan la esencia misma del derecho de recurrir del fallo. Al respecto, la Corte ha establecido que "no basta con la existencia formal de los recursos, sino que éstos deben ser eficaces", es decir, deben dar resultados o respuestas al fin para el cual fueron concebidos (párr. 161).

En consecuencia, a pesar de que la CoIDH hace un reconocimiento del margen de apreciación a favor de los Estados, éste queda condicionado, en principio, a que no se puede impedir la interposición del recurso contra las decisiones judiciales, lo cual involucra un margen moderado siempre que éste, el recurso, sea eficaz.

En tanto, la protección judicial fue estimada en el caso Cantos vs. Argentina (2002), donde el Estado denegó el acceso a la justicia y no reparó de manera efectiva los perjuicios de la víctima. Por eso, la Corte instituye que las restricciones a los derechos no pueden implicar la negación del derecho mismo, y que si bien los Estados, en el marco de su discrecionalidad, pueden establecer reglas para el acceso a la justicia, éstas no deben anularlo.

En esa misma dirección se encuentra la sentencia Almonacid Arellano vs. Chile (2006), donde se valoró la responsabilidad internacional por falta de investigación, sanción y falta de reparación, pues en virtud de una ley de amnistía se impedía juzgar a los posibles responsables. Esto llevo a que la Corte aclarara la inexistencia de un margen de apreciación para las amnistías de crímenes de lesa humanidad, puesto que "según el corpus iuris del 
derecho internacional, un crimen de lesa humanidad es en sí mismo una grave violación a los derechos humanos y afecta a la humanidad toda" (párr. 105). Configurando así el estatus nulo del margen de discrecionalidad en materia de amnistías relacionadas con crímenes de lesa humanidad, como también quedó reconocido, verbigracia, en el caso la Cantuta vs. Perú (2006), cuando se afirma que los crímenes contra la humanidad "no pueden quedar impunes, son imprescriptibles y no pueden ser comprendidos dentro de una amnistía (supra párr. 152)" (párr. 225).

Para el 2015, en el Informe de Fondo No. 43/15, la CIDH se pronunció sobre el caso de Adriana Beatriz Gallo, Ana María Careaga y Silvia Maluf de Christin contra Argentina, que se fundó en el hecho de que las peticionarias fueron destituidas como juezas por un jurado de enjuiciamiento que no cumplía con los requisitos de imparcialidad e independencia, siendo un juicio político y no penal.

Así, la CIDH estudió dos aspectos principales: por un lado, la posible violación de derecho por la decisión que tomó el jurado, y, por el otro, el derecho de libre expresión y pensamiento. Frente al primer asunto, la $\mathrm{CIDH}$ sostuvo que los estándares internacionales son claros en cuanto a que "la función jurisdiccional debe llevarse a cabo libre de presiones externas y, por lo tanto, no puede ser objeto de un control político, basado en el criterio de discrecionalidad política, sino jurídico o sancionatorio en caso de comisión de faltas disciplinarias graves o incompetencia" (párr. 198).$^{29}$ De suerte que se restringe el margen de apreciación de los Estados en este tópico, teniendo en cuenta, igualmente, que "Los juicios políticos en los que se discute la remoción de miembros del Poder Judicial no son contrarios a la Convención per se, siempre y cuando en el marco de aquellos, se cumplan las garantías del artículo 80. y existan criterios que limiten la discrecionalidad del juzgador con miras a proteger la garantía de independencia”, como expuso la $\mathrm{CoIDH}$ en el caso Rico vs. Argentina (2019). Ahora, en relación con el derecho de libre expresión y pensamiento de las juezas, la Comisión empleó distintos fallos de la Corte ${ }^{30}$ para apuntar que existe un margen, sólo que reducido. ${ }^{31}$

29 La CIDH llega a tal conclusión tras analizar los estándares fijados por la CoIDH en casos como Tribunal Constitucional vs. Perú (2001) o Apitz Barbera y otros vs.Venezuela (2008).

30 Por ejemplo, a Claude Reyes y otros vs. Chile (2006), Herrera Ulloa vs. Costa Rica (2004) y Ricardo Canese vs. Paraguay (2004), entre otros.

31 Con todo, también se señaló que el derecho a la libertad de expresión no es absoluto y es susceptible de limites cuando se trata de servidores públicos. Estas limitaciones se encuen- 
En ese marco también se hicieron relevantes las determinaciones ofrecidas en el caso Perozo y otros vs.Venezuela (2009), en el que se discute la responsabilidad del Estado por acciones y omisiones frente al hostigamiento y agresiones físicas y verbales que tuvieron que ver con la obstaculización de labores periodísticas. Entonces, la Corte estudió la libertad de pensamiento y de expresión para reiterar que existen criterios legítimos para la restricción del derecho por parte del Estado:

A fin de evitar la arbitrariedad en el ejercicio del poder público, las restricciones en esta materia deben hallarse previamente establecidas en leyes subordinadas al interés general, y aplicarse con el propósito para el cual han sido establecidas [...] Corresponde al Estado demostrar que ha cumplido con los anteriores requisitos al establecer restricciones al acceso a la información bajo su control (párr. 375).

Con anterioridad, en 2008, la Corte ya había indicado, en Kimel vs. Argentina, directamente con la libertad de información, que, si bien la $\mathrm{CADH}$ prohíbe la censura previa, contempla la posibilidad de exigir responsabilidades ulteriores con un "carácter excepcional y no deben limitar, más allá de lo estrictamente necesario, el pleno ejercicio de la libertad de expresión y convertirse en un mecanismo directo o indirecto de censura previa" (párr. 54).

Posteriormente, la Corte aplicó estos parámetros en el caso Mémoli vs. Argentina (2013), donde se concluyó que las condenas impuestas por el Estado no configuraron una violación a la libertad de expresión, sino que estaban dentro de los parámetros de la Convención. Debido a ello, se reconoce un margen de apreciación moderado frente a la libertad de pensamiento y expresión, no obstante, siendo nulo en relación con las censuras previas, como había quedado en el caso Palamara Iribarne vs. Chile (2005), donde, al mismo tiempo, la Corte hizo observaciones sobre la discrecionalidad de los Estados a la hora de restringir el derecho de la libertad de expresión en la justicia penal militar. En ella, el Estado debe garantizar el debido proceso y la protección judicial, con lo cual la discrecionalidad en materia de la jurisdicción penal militar es reducida.

tran sometidas a los siguientes requisitos: a) sean definidas en forma precisa y clara a través de una ley formal y material; b) sean orientadas al logro de objetivos imperiosos autorizados por la $\mathrm{CADH}, \mathrm{y}$ c) sean necesarias en una sociedad democrática, idóneas para lograr el objetivo que pretende lograr y estrictamente proporcionales a la finalidad perseguida (párr. 236). 
En la valoración del caso Efraín Ríos Montt (1993), la CIDH hará mención a la discrecionalidad de los Estados en razón a los derechos políticos, diciendo que en ellos "puede surgir el margen de apreciación permitido por el derecho internacional” (párr. 24) y agregando que éste, el margen, "debe analizarse de acuerdo a las circunstancias del caso y las concepciones jurídicas prevalecientes en el periodo histórico. Nuevamente aquí la Comisión debe reafirmar el carácter restrictivo con que debe utilizar ese margen de apreciación, el cual debe ser siempre concebido tendiente al refuerzo del sistema y sus objetivos" (párr. 31). Para sostener ello, la CIDH reflexiona la idiosincrasia guatemalteca, la de los países centroamericanos y el Tratado General de Paz y Amistad (1923), donde se comprometen a no permitir la dirección a un jefe, autoridad o familiar de los responsables de un golpe de Estado y pactan el principio de no reelección (párrs. 26 y 27). Esto con el fin, entonces, de estimar el consenso y la historia como elementos esenciales para abstenerse de conocer la denuncia elevada.

Reflexión equivalente quedó en el caso Statehood Solidarity Committee vs. Estados Unidos (2003), en el que se estimó "el grado de deferencia que corresponde otorgar a los Estados en la organización de sus instituciones políticas para dar efecto al derecho al voto y a participar en el gobierno" (párr. 101), salvo que se afecte la esencia y la eficacia del derecho de participar en el gobierno. Empero, en esta oportunidad halló injustificada la limitación y fijó que la restricción a los derechos políticos debe ser "razonable, objetiva y proporcionada, teniendo debidamente en cuenta el contexto de su sistema político" (párr. 110).

Por su parte, la CoIDH, en el caso Castañeda Gutman vs. México (2008), reconoció, partiendo del artículo 23 convencional, que son los Estados quienes deben estructurar su modelo electoral y que no le compete a ella tachar de inviable uno u otro modelo, pues dicha atribución es de la ciudadanía en los ejercicios de deliberación propios de las sociedades democráticas. De este modo, la Corte consideró que "el derecho internacional no impone un sistema electoral determinado ni una modalidad determinada de ejercer los derechos a votar y a ser elegido" (párr. 162). A diferencia de otros temas, los derechos consagrados en el artículo 23.1 de la CADH no asignan restricción alguna al sistema electoral de los Estados, sino que su diseño queda atado a las decisiones discrecionales que se adopten en el derecho interno. Ciertamente, 
La Convención Americana establece lineamientos generales que determinan un contenido mínimo de los derechos políticos y permite a los Estados que dentro de los parámetros convencionales regulen esos derechos de acuerdo a sus necesidades históricas, políticas, sociales y culturales, las que pueden variar de una sociedad a otra, e incluso en una misma sociedad, en distintos momentos históricos (párr. 166).

Por tal motivo, se advierte un margen de apreciación de alto grado frente al sistema electoral, pero moderado frente a las limitaciones de los derechos políticos, que deben responder a ámbitos legales, legítimos, necesarios, proporcionales y que no promuevan la discriminación. ${ }^{32}$

Dicho margen se aplica, igualmente, en el tópico del derecho a la nacionalidad, tal como se estudió en 2001 por la Comisión en el caso Álvaro José Robelo González vs. Nicaragua, cuando se recalcó que "cada Estado estipula, de manera soberana, la normativa sobre adquisición, pérdida y recuperación de la nacionalidad" (párr. 49); ello contempla la existencia de un margen amplio.

En ese mismo año se introdujo el margen de apreciación frente a los temas de inmigración en el Informe No. 51/01. Pese a que el Estado denunciado desplegó argumentos para sustentar su alto grado de discrecionalidad, citando incluso el caso North Sea Conntinental Sheif de 1969 de la Corte Internacional de Justicia, entre otros, la Comisión "acepta que los Estados históricamente han dispuesto de una discreción considerable en el derecho internacional para controlar el ingreso de extranjeros a su territorio. Pero esto no significa que la discreción no tenga que ser ejercida de conformidad con las obligaciones internacionales de los Estados en materia de derechos humanos" (párr. 177). Así pues, la CIDH llega a la determinación de que, si bien el margen de apreciación existe sobre el tema de inmigración, éste no tiene un carácter absoluto.

La dirección se mantuvo en el caso de 2016, Trabajadores Indocumentados vs. Estados Unidos. En el caso referenciado se reiteró que el margen de los Estados no puede llevar a avalar condiciones o medidas de discriminación:

En otras palabras, el Estado y los particulares, como los empleadores, pueden abstenerse de establecer una relación laboral con migrantes en situación irregular. Sin embargo, cuando se entabla una relación laboral, la Comisión considera que

32 En igual sentido, tratándose de restricciones como las multas y la inhabilitación al sufragio pasivo, se puede acudir al caso Leopoldo López Medina vs.Venezuela (2011). 
las protecciones conferidas por ley a los trabajadores, con la gama completa de derechos y obligaciones abarcados, deben aplicarse a todos los trabajadores sin discriminación, sean documentados o indocumentados (párr. 76).

De tal modo, se vinculan estas afirmaciones con el tratamiento ofrecido a la prohibición de discriminación, que fue objeto en el caso Duque vs. Colombia (2016) ante la Corte, y en el que se analizó la negativa de otorgar una pensión de sobreviviente, al no contar la calidad de beneficiario conforme con la ley. Con todo, el Estado mostró que la jurisprudencia interna, desde 2007, ya favorecía la petición efectuada, con lo cual se encontraba en trámite. No obstante, la Corte expresó que la jurisprudencia constitucional citada no era prueba suficiente para desvirtuar la ausencia de responsabilidad y declaró responsable al Estado por violación del artículo 24 convencional, sustentado en la ineficacia del sistema pensional.

Empero, en dicha decisión se hace relevante el voto parcialmente disidente de Eduardo Vio Grossi, quien fija su inconformidad respecto de la declaración de la violación del artículo 24 de la $\mathrm{CADH}$, en la medida en que la obligación discutida, el otorgamiento de la pensión, no yace en el marco del derecho internacional al momento que fue discutida internamente y, asimismo, enfatiza que el Estado debe tener un margen de apreciación sobre el asunto.

Se debe tener presente, a este respecto, que la jurisdicción doméstica, interna o exclusiva del Estado está conformada por todas aquellas materias o facetas de las mismas, no reguladas por el Derecho Internacional, lo que implica, entonces, que en la medida en que una materia es contemplada por este último, deja de ser, en esa medida, un asunto de aquel. De allí se desprende, entonces, que el derecho internacional no abarca todas las actividades humanas, dejando las que no regula, bajo el imperio del derecho nacional o interno [...] Lo que se sostiene es que, para que sean materia de derecho internacional, deben ser contemplados por alguna fuente de derecho internacional, esto es, un tratado, la costumbre o los principios generales de derecho aplicables a los Estados Partes de la Convención y, eventualmente, respecto del Estado de que se trate, por un acto jurídico unilateral del mismo, todo lo cual no acontece en el caso de autos en lo referente al periodo 2002 a 2007 y/o 2009.

La decisión precedente llevó a que Colombia, en el Informe de Fondo No. $122 / 18$, aceptara que había incurrido en discriminación a las mujeres 
privadas de la libertad al prohibirles las visitas íntimas a sus parejas del mismo sexo, y adopta una serie de medidas y recomendaciones solicitadas por la CIDH para adecuar la restricción que era de 1994 y que no tenía sostén a la fecha para conservarla.

Por otro lado, para el servicio militar obligatorio y libertad de conciencia, en el caso Cristián Daniel Sahli y otros vs. Chile (2005) se acotó que en la experiencia interamericana no había antecedentes sobre el tema de objeción de conciencia y que el derecho no se hallaba consagrado explícitamente en la CADH; sólo se vincula con aquellas personas que pueden ser consideradas como "objetoras", según el artículo 6.3.b de la CADH. Por este motivo, la CIDH se remite a normativa de otros sistemas internacionales de protección, y basado en ello, "La Comisión opina que el servicio militar obligatorio no está prohibido por la Convención y que el artículo 6 (3)(b) prevé específicamente el servicio militar en los países que no reconocen a los objetores de conciencia. En consecuencia, la Comisión concluye que el Estado chileno no violó el artículo 11 en perjuicio de los peticionarios en este caso" (párr. 105). Concluyendo que el establecimiento del servicio militar obligatorio, como el derecho a la objeción de conciencia, queda sometido a una discrecionalidad de los Estados, sin que por ello se puedan desconocer los límites del derecho internacional humanitario, para el caso de conflictos, y la existencia, en caso que suceda, de la objeción de conciencia en los ordenamientos internos.

De igual manera, desde 1988 se ha reconocido la posibilidad de establecer la colegiatura profesional obligatoria. Esto en los informes 9777 y 9718 contra Argentina, en donde la Comisión avaló la discrecionalidad de los Estados para fijar el requisito de la colegiatura obligatoria para ejercer la profesión jurídica. Ello empleando la Opinión Consultiva No. 5 de 1985 y afirmando que no toda ley de colegiación es de por sí violatoria de la CADH.

Esta discrecionalidad, de cierta manera, se reproduce en la viabilidad de declarar estado de emergencia y las acciones para atenderlo, cuando, en el 2000, la CIDH, en el caso Walter Humberto Vásquez vs. Perú, dijo que "Aunque en general recae en los propios Estados y sus poderes públicos en particular el «margen de apreciación» para determinar la necesidad de declarar el estado de emergencia, por tener un conocimiento directo e inmediato de las circunstancias de hecho por las que atraviesa el país, ese margen de apreciación no es ilimitado". 
Los límites a ese margen están contemplados en el artículo 27 de la CADH y fueron desarrollados en la Opinión Consultiva No. 8 de 1987: "En consecuencia, el margen de apreciación a nivel interno está acompañado por una supervisión interamericana. La Comisión debe valorar apropiadamente aspectos relevantes, tales como naturaleza de los derechos afectados por la suspensión, la circunstancias que motivaron el estado de emergencia y su duración" (párr. 55). En esta medida se puede afirmar que la Comisión se inclinó por un margen de apreciación moderado para las situaciones de emergencia.

Esta restricción moderada también fue admitida para las reservas procesales internas, y así lo dispuso la Comisión en el Informe No. 96/19, cuando aseveró que es permitido efectuar reservas de información respecto a personas ajenas al proceso, "pues la divulgación de ciertos contenidos en una etapa preliminar de las investigaciones podría obstruirlas o causar perjuicios a las personas". No obstante, dicha reserva "no puede redundar en perjuicio de las víctimas".

Frente a la protección de la intimidad, en el caso Atala Riffo vs. Chile (2012) se destaca, para el tema, el voto parcialmente disidente del juez Alberto Pérez, quien estimó que no hay un consenso interamericano respecto a la familia, así:

Estoy de acuerdo con el criterio de interpretación evolutiva que considera a la Convención Americana como un instrumento viviente que ha de entenderse de acuerdo con las circunstancias actuales, pero en el entendido de que para avanzar en ese terreno es necesario que exista un consenso, un espacio de coincidencia o una convergencia de estándares entre los Estados partes (ver supra, párr. 9). Tal es lo que ocurre en el caso del reconocimiento de que la discriminación fundada en la orientación sexual debe entenderse prohibida (párrs. 83 a 93 de la Sentencia) [...] No puede decirse que ocurra lo mismo en relación con la evolución de la noción de familia y su calidad de base o elemento esencial o natural de la sociedad, que sigue estando presente incluso en las Constituciones de numerosos Estados partes (supra, párr. 19).

Conforme a lo anterior, el juez vio como "necesario reconocer un margen de apreciación nacional”, por lo menos en lo que respecta a la noción de familia.

Esta interpretación puede verse como discrepante, también, a lo apuntado por la Comisión y la Corte sobre los derechos reproductivos: en 2004, 
Esta revista forma parte del acervo de la Biblioteca Jurídica Virtual del Instituto de Investigaciones Jurídicas de la UNAM

caso Sánchez Villalobos y otros vs. Costa Rica, la CIDH terminó hablando de un carácter restrictivo del margen de apreciación, y, en 2012, la CoIDH, en Artavia Murillo y otros vs. Costa Rica, de cierta forma lo confirma. Efectivamente, en ambos casos se estudió la prohibición del procedimiento de fecundación in vitro tras una decisión de la sala constitucional de la Corte Suprema de Justica de Costa Rica. Aquí el término margen de apreciación se emplea de manera expresa, por un lado, traída por la representación de víctimas y, por el otro, por el Estado en sus alegatos.

Empero, dicha categoría no fue ajena a la Corte que usó resoluciones del sistema europeo en relación con el margen de apreciación y el derecho a la vida. ${ }^{33}$ Con sustento en ello, la Corte concluyó que, a pesar de que no hay un vínculo entre embrión y persona según los instrumentos internacionales, bajo una interpretación evolutiva "el objeto y fin del artículo 4.1 de la Convención es que no se entienda el derecho a la vida como un derecho absoluto, cuya alegada protección pueda justificar la negación total de otros derechos" (párr. 257), con lo cual, según la Corte, "la protección del derecho a la vida [...] es gradual e incremental según su desarrollo, debido a que no constituye un deber absoluto e incondicional, sino que implica entender la procedencia de excepciones a la regla general" (párr. 264). Por esta razón la CoIDH identificó un grado de deferencia que eximió de responsabilidad al Estado por el artículo 4.1 de la CADH, sólo que condenó por los otros derechos invocados.

No obstante, posiblemente el tratamiento más amplio que fue detectado, en cuanto a número de menciones, tiene vínculo con el artículo 21 de la $\mathrm{CADH}$; es decir, con el derecho de propiedad, pero con nexo a los pueblos ancestrales. Entre los casos hallados estuvieron: Comunidades indígenas miembros de la Asociación Lhaka Honhat (Nuestra Tierra) vs. Argentina (2020), Saramaka vs. Surinam (2007), Yanke Axa vs. Paraguay (2006), Comunidad Indígena Sawhoyamaxa vs. Paraguay (2006), Comunidad Moiwana vs. Surinam (2005), Comunidad Myagna (Sumo) Awas Tingni vs. Nicaragua (2001) y Yatama vs. Nicaragua (2005). En donde se erigió que estos pueblos cuentan con "el derecho de ser titulares de la tierra que han usado y ocupado tradicionalmente durante siglos". ${ }^{34}$ De tal suerte que la regulación del

33 Entre los casos citados del sistema europeo están: Paton vs. Reino Unido (1980), Vo. vs. Francia (2004), A, B y C vs. Irlanda (2010), Evans vs. Reino Unido (2007), S. H. vs. Austria (2010) y Costa y Pavan vs. Italia (2010).

34 Como se manifestó, por ejemplo, en los casos Yanke Axa vs. Paraguay (párr. 121) y Saramaka vs. Surinam (párr. 85). 
Esta revista forma parte del acervo de la Biblioteca Jurídica Virtual del Instituto de Investigaciones Jurídicas de la UNAM

territorio ancestral por parte de los Estados tiene un restringido margen de apreciación:

La elección y entrega de tierras alternativas, el pago de una justa indemnización o ambos no quedan sujetas a criterios meramente discrecionales del Estado, deben ser, conforme a una interpretación integral del Convenio No. 169 de la OIT y de la Convención Americana, consensuadas con los pueblos interesados, conforme a sus propios procedimientos de consulta, valores, usos y derecho consuetudinario. ${ }^{35}$

Justamente, en un caso de pueblos ancestrales se dio paso, también, a razonar sobre el margen de apreciación frente a los derechos económicos, sociales y culturales, sólo que en votos disidentes. Por ejemplo, en el caso Nuestra Tierra vs. Argentina (2020) surgirán dos votos parcialmente disidentes sobre la temática, los de los jueces Humberto Antonio Sierra Porto ${ }^{36}$ y Eduardo Vio Grossi ${ }^{37}$ —éste último, en diversos temas, cita explícitamente la locución y el artículo del sistema europeo sobre el margen-. ${ }^{38}$ Las posiciones de ambos sobre el derecho a la seguridad social ya habían sido expuestas en el caso Muelles Flores vs. Perú (2019), lo que configura, en el fondo, una crítica clara y no casual a la posición mayoritaria de la Corte de extender su

35 Cfr. caso Comunidad Indígena Yakye Axa vs. Paraguay (párrs. 144, 145, 146, 148 y 151), caso del Pueblo Saramaka vs. Surinam (párr. 127) y Comunidades indígenas miembros de la Asociación Lhaka Honhat (Nuestra Tierra) vs. Argentina (nota al pie 102).

36 "Los DESCA por naturaleza son derechos que dependen en su satisfacción de la existencia de condiciones materiales. Igualmente, no se trata de derechos «homogéneos», ya que tienen un alcance diverso según las capacidades económicas y las características propias del Estado y su aparato burocrático. En esta medida no existiría un estándar uniforme de cumplimiento de estas obligaciones, sino que su contenido podría depender de las acciones determinadas que cada Estado esté en posibilidades de realizar”. Voto parcialmente disidente Humberto Antonio Sierra Porto, caso Nuestra Tierra vs. Argentina.

37 "La existencia de tales derechos no es objeto del presente escrito. Lo que, en cambio, se sostiene aquí es únicamente que la Corte, contrariamente a lo indicado en la Sentencia, carece de competencia para conocer, al amparo de lo previsto en el artículo 26 de la Convención, de las violaciones de aquellos, esto es, que las presuntas vulneraciones de esos derechos no son susceptibles de ser justiciables ante ella”. Voto parcialmente disidente Eduardo Vio Grossi, caso Nuestra Tierra vs. Argentina.

38 Efectuada en los votos disidentes para los casos López y otros vs. Argentina (2019), Hernández vs. Argentina (2019), Asociación Nacional de Cesantes y Jubilados de la Superintendencia Nacional de Administración Tributaria vs. Perú (2019), Díaz Loreto y otros vs. Venezuela (2019) y en el voto concurrente del caso Gómez Virula y otros vs. Guatemala. 
competencia contenciosa a disposiciones que no están claramente sujetas a dicha capacidad. Así, una interpretación conjunta puede llevar a observar que la Corte reconoce la justiciabilidad de estos derechos, pero su forma de implementación y regulación cuentan con un margen amplio de apreciación por parte de los Estados.

Esta materia sería la última detectada de acuerdo a la metodología propuesta, y daría una presentación sucinta de las variaciones y los tópicos en el sistema americano sobre el margen de apreciación; llevando a que no subsista una homogeneidad del concepto ni de la doctrina en sí, y, por consiguiente, que se requieran ciertas observaciones aclaratorias.

\section{OBSERVACIONES FRENTE A LOS PARÁMETROS \\ DE APLICABILIDAD DEL MARGEN}

Un elemento primordial de la concepción del margen de apreciación en el contexto interamericano es el presupuesto, que, al igual que en la esfera europea, no tiene una noción única y extendida. Por el contrario, ésta suele ser dependiente de la construcción jurisprudencial y sólo, de modo posterior, objeto de los modelos aportados por la doctrina. Inclusive la doctrina suele oscilar entre posiciones extremas: sea la de una negativa plena en su aplicación, por suponer una eliminación de la fuerza vinculante del derecho internacional y de las garantías ya reconocidas a las personas, o sea en contraposición, la de una validación íntegra que recopila la percepción de una soberanía absoluta como un elemento esencial de la construcción de los Estados.

Con todo, lo cierto es que el margen de apreciación no puede ser distante del todo al significado de la soberanía. Más allá de las diversas postulaciones que se han surtido sobre ella, "Si queremos evitar la confusión deberemos restringir el uso de «soberanía» a lo que propiamente se refiere:

39 Véanse, entre otros: Hillgruber, Christian, “Soberanía. La defensa de un concepto jurídico”, InDret, núm. 1, enero-marzo de 2009, pp. 1-20; Marshall Barberán, Pablo, "La soberanía popular como fundamento del orden estatal y como principio constitucional”, Revista de Derecho, vol. 35, núm. 2, julio-diciembre de 2010, pp. 245-286; Balbontin Gallo, Cristóbal, "Volver a los orígenes: la soberanía, un concepto fundamental para comprender el derecho público", Revista Chilena de Derecho, vol. 45, núm. 3, septiembre-diciembre de 2018, pp. 825-834. 
potencia absoluta y perpetua bodiniana y hobbesiana; poder absoluto, ilimitado, indivisible, inapelable, incontrolable, independiente ad extra y supremo ad intra", ${ }^{40}$ lo que lleva a diferenciar la soberanía como atributo, y el concepto arraigado de soberano, como titular. Justamente en ellos "el ejercicio de poder va unido al territorialismo y a la existencia de un espacio delimitado por fronteras sobre el que se puede ejercer un control efectivo", ${ }^{41}$ permitiendo que se hable de las manifestaciones de una soberanía interna y externa en relación con el territorio. ${ }^{42}$ De estos ejercicios se aduce, por ejemplo, las nociones a nivel interno de Poder Constituyente y la propia libertad configurativa del legislador, ${ }^{43} \mathrm{y}$ a nivel internacional, la autodeterminación, el reconocimiento de los Estados como sujetos predominantes del derecho internacional público y su capacidad de obligarse ex consensu advenit vinculum.

Ahora, tanto la aplicación como las consecuencias son totalmente disímiles: tal como no pueden compararse estrictamente la Constitución o ley con los tratados internacionales, no es equivalente el ejercicio de la soberanía a nivel interno que a nivel internacional. Ciertamente, si se asume que el ejercicio de la soberanía puede estar regulada de formas distintas, se debe entender que el sentido interno de ésta se basa en una visión estatal con preponderancia a la centralización —incluso sin importar si se está frente a Estados unitarios o compuestos - que se facilita por la identificación notoria de funciones, órganos y normativas, mientras que, a nivel internacional, el Estado no es Estado, estrictamente, sino un sujeto que interviene en igualdad con otros de la misma índole y que será regulado por la manifestación de su voluntad explícita — por decisión o repetición - en una perspectiva pactista. Adicionalmente, en lo internacional yacen un pluralismo y una coexistencia tanto normativas como competenciales ante la ausencia de una

40 Pereira Menaut, Antonio Carlos, "Después de la soberanía”, Revista de Derecho Político, núm. 50, enero-abril de 2001, p. 62.

${ }_{41}$ Cancela Outeda, Celso, El proceso de constitucionalización de la Unión Europea: "de Roma a Niza”, Santiago de Compostela, Universidad de Santiago de Compostela, 2001, p. 41.

42 Cfr. Fuentes-Contreras, Édgar Hernán, "Del Estado constitucional al Estado convencional de derecho. Estudio preliminar sobre el modelo del Estado convencional de derecho en el contexto latinoamericano", Revista Jurídica Digital UANDES, vol. 3, núm. 2, julio-diciembre de 2019, pp.13-42.

43 Cfr. Fuentes-Contreras, Édgar Hernán, Legislación en sentido material, Bogotá, Grupo Editorial Ibáñez y otro, 2018. 
centralización. Por ello se vuelve relevante el principio de subsidiariedad y complementariedad, con el fin de una armonización sistémica ${ }^{44}$ en lugar de un principio de jerarquía, que suele ser la base de la comprensión estatal.

Como consecuencia, su funcionamiento no puede ser idéntico; ni en su teoría ni en su práctica. Esta última debido a que, además, no tendrá siempre el mismo sustento normativo.

En esas circunstancias, y pese a que las normativas como la Constitución y las leyes comparten con buena parte de los tratados internacionales los atributos de textura abierta y su pretensión de perdurabilidad, al igual que contenidos como los derechos humanos, ${ }^{45}$ su racionalidad es distante y, en todo caso, dependiente de la consolidación de un acuerdo fundamental, no sólo en lo procedimental. ${ }^{46}$ Bajo ese punto de vista, la coherencia del ejercicio de la soberanía, en lo interno e internacional, se deriva de una relación inversamente proporcional; es decir, que está circunscrita por el nivel de participación de aquellos sujetos que serán regulados, teniendo mayor legitimidad lo que es pactado que aquello que es otorgado o impuesto.

Así las cosas, examinar el concepto de margen de apreciación nacional deberá surgir, en primer momento, desde su análisis como ejercicio de la soberanía internacional, que manifiesta directamente el reconocimiento de la soberanía interna, la propia buena fe como principio del derecho internacional y del principio de subsidiaridad, ${ }^{47}$ "en virtud del cual se presume que los Estados están en mejor posición para determinar la forma más adecuada de ajustarse a sus compromisos jurídicos internacionales". ${ }^{48}$

44 Véase Contreras, Pablo, "Control de convencionalidad, deferencia internacional y discreción nacional en la jurisprudencia de la Corte Interamericana de Derechos Humanos”, Ius et Praxis, año 20, núm. 2, julio-diciembre de 2014, pp. 235-274.

45 Cfr. Mena Parras, Francisco Javier, "Democracy, Diversity and the Margin of Appreciation: A Theoretical Analysis from the Perspective of the International and Constitutional Functions of the European Court of Human Rights”, REEI, núm. 29, julio-diciembre de 2015, pp. 1-18.

46 Cfr. Pereira Menaut, Antonio Carlos, Doce tesis sobre la política, México, UNAM, 2008.

47 "El concepto de consenso contribuye a explicar el funcionamiento de la noción del margen de apreciación nacional, manifestándose como una herramienta al servicio del principio de subsidiariedad y basada en el carácter voluntarista relativista del DI público”. Pascual Vives, Francisco José, "El margen de apreciación nacional en los tribunales regionales de derechos humanos: una aproximación consensualista”, Anuario Español de Derecho Internacional, vol. 29, 2013, p. 262.

48 Martínez Estay, José Ignacio, op. cit., p. 379. 
Con tal referencia, al introducir esta doctrina en el derecho interamericano se debe observar, inicialmente, que su cimiento normativo se encuentra en la CADH: desde el preámbulo, ${ }^{49}$ pasando por los artículos 1.1, 2o. y 46.1 a que, tácitamente, incluyen la subsidiariedad y la complementariedad. Esto acreditaría su empleo, como se ha efectuado en la práctica de la Comisión y de la Corte, sólo que en su abordaje no se ha tomado en cuenta que la categoría es contendedora de varios sentidos que deberían ser precisados:

\section{TABla 3. Sentidos del "Margen de apreciación NACIONAL” EN EL SISTEMA INTERAMERICANO DE DeRECHOS Humanos}

\begin{tabular}{|c|l|}
\hline \multicolumn{2}{|c|}{ Margen de apreciación nacional } \\
\hline Sentidos & \multicolumn{1}{c|}{ Descripción } \\
\hline Criterio & $\begin{array}{l}\text { Desde el ámbito interpretativo, se encarga de restringir la inter- } \\
\text { pretación judicial a nivel internacional, según la existencia o no } \\
\text { de un consenso } \\
\text { interpretación auténtica de los partes y, adicionalmente, favorece la } \\
\text { jor posición para evaluar la razonabilidad de una restricción de } \\
\text { acuerdo al contexto. }\end{array}$ \\
\hline
\end{tabular}

49 "PreÁmbulo. Los Estados Americanos signatarios de la presente Convención, Reafirmando su propósito de consolidar en este Continente, dentro del cuadro de las instituciones democráticas, un régimen de libertad personal y de justicia social, fundado en el respeto de los derechos esenciales del hombre; Reconociendo que los derechos esenciales del hombre no nacen del hecho de ser nacional de determinado Estado, sino que tienen como fundamento los atributos de la persona humana, razón por la cual justifican una protección internacional, de naturaleza convencional coadyuvante o complementaria de la que ofrece el derecho interno de los Estados americanos...”. Convención Americana sobre Derechos Humanos (1969).

50 "La doctrina del margen de apreciación nacional se presenta cuando no es posible verificar la existencia de consenso internacional respecto a la cuestión a resolver y, al mismo tiempo, cuando las circunstancias del caso ameritan una deferencia hacia las autoridades estatales para que interpreten el sentido dado a la norma internacional”. López Alfonsín, Marcelo Alberto, op. cit., p. 69. "On the other hand the use of the doctrine will allow to be taken customs, traditions, and the state's history, into account". Butler, Petra, "Margin of Appreciation. A Note Towards a Solution for the Pacific?", Victoria University of Wellington Law Review, vol. 39, núm. 4, diciembre de 2008, p. 706. 


\begin{tabular}{|c|c|}
\hline \multicolumn{1}{|c|}{ Margen de apreciación nacional } \\
\hline Sentidos & \multicolumn{1}{|c|}{ Descripción } \\
\hline Derecho & $\begin{array}{l}\text { De titularidad de los Estados, como sujetos del derecho inter- } \\
\text { nacional, y que garantiza el respeto de su voluntad al momento } \\
\text { de generar las obligaciones internacionales. Del mismo modo, } \\
\text { es atribuible, como derecho, a los grupos sociales y étnicos y a la } \\
\text { sociedad en sí misma, en su posibilidad del ejercicio democráti- } \\
\text { co y autodeterminación. }\end{array}$ \\
\hline Herramienta & $\begin{array}{l}\text { De interacción, armonización y de encuentro entre el derecho } \\
\text { nacional y el internacional, con el fin de articular competencias } \\
\text { y piezas normativas de los diferentes ordenamientos ante la co- } \\
\text { existencia de normas y competencias. }\end{array}$ \\
\hline Competencia & $\begin{array}{l}\text { De regulación o de creación normativa, en razón de que el Es- } \\
\text { tado y sus órganos no son meros aplicadores de las normas in- } \\
\text { ternacionales y que tienen: a) su subsistencia, en la necesidad } \\
\text { incluyen conceptos abstractos, } \\
\text { mento, a la autorrestricción, y b) su límite, en la afectación del } \\
\text { núcleo esencial del derecho humano regulado, ante el cual se } \\
\text { acredita la intervención jurisdiccional internacional. }\end{array}$ \\
\hline
\end{tabular}

En esta perspectiva, ha de tenerse en cuenta que si bien la doctrina del margen de apreciación no ha sido consolidada con cierta rigurosidad conceptual en los sistemas regionales, no deja de ser un elemento que se adecuaría y articularía a un sistema normativo policéntrico y no organizado desde la mera jerarquía. Conjuntamente, el margen no puede ser visto como una forma de negar la posibilidad de herramientas interpretativas ${ }^{52}$ como aquella que aboga por una percepción evolutiva o dinámica, sino

51 En ese ámbito, resulta relevante la diferencia entre normas de aplicación y normas de definición, puesto que esta diferencia también genera qué tipo de margen puede ostentar el Estado. Kratochvíl, Jan, op. cit.

52 Cfr. Burgorgue-Larsen, Laurence, "El contexto, las técnicas y las consecuencias de la interpretación de la Convención Americana de los Derechos Humanos”, Estudios Constitucionales, vol. 12, núm. 1, enero-junio de 2014, pp. 105-161. 
que su uso se basa en la diferencia entre interpretación y construcción, ${ }^{53}$ al tiempo que coordina la función jurisdiccional internacional no asilada a un sistema complejo de interacción, pero que, de cualquier manera, pretende evitar un elitismo epistemológico de lo judicial ${ }^{54}$ y el riesgo de extender las preferencias judiciales como verdades jurídicas absolutas, ajenas a la realidad social. En consecuencia, el correcto uso del margen de apreciación más que eximir a los Estados de la responsabilidad internacional, les permite, como sujeto del derecho internacional, una autonomía mediada para sortear las dificultades relacionadas con los derechos y obligaciones que no gozan de claridad normativa.

\section{CONCLUSIONES}

Sin duda, el margen de apreciación nacional "is a complex, sophisticated and defensible intellectual instrument for international bodies supervising polycentric rights claims", ${ }^{55}$ que pese a tener una mejor recepción en la CIDH, ${ }^{56}$ no puede ser tomada como ajena a la realidad interamericana y que requiere un tratamiento más allá de lo nominativo. Esto en razón de que incluso las afirmaciones de no existencia frente a ciertos tópicos que han sido sostenidas en las decisiones de la CIDH y la CoIDH terminan abriendo una puerta para que puedan ser aplicados en otros espacios de interpretación de la Convención, que, por demás, necesitan imperiosamente contar con esa posibilidad.

53 Cfr. Laise, Luciano D., "La distinción entre interpretación y construcción: una visión crítica del originalismo del significado público", Ius et Praxis, vol. 25, núm. 3, diciembre de 2019, pp. 249-276.

54 Cfr. López Hidalgo, Sebastián, Reflexiones acerca de la legitimidad democrática de la justicia constitucional en Ecuador, Quito, UASB, 2018; Laise, Luciano D., “PPuede la expansión del derecho al acceso a la justicia potenciar al activismo judicial?”, Anuario Iberoamericano de Justicia Constitucional, vol. 24, núm.1, 2020, pp. 147-173.

55 McGoldrick, Dominic, "A Defence of the Margin of Appreciation and an Argument for its Application by the Human Rights Committee”, International and Comparative Law Quarterly, vol. 65, núm. 1, enero-marzo de 2016, p. 58.

56 Núñez Poblete, Manuel, "Sobre la doctrina del margen de apreciación nacional. La experiencia latinoamericana confrontada y el thelos constitucional de una técnica de adjudicación del derecho internacional de los derechos humanos", en Núñez Poblete, Manuel y Acosta Alvarado, Paola Andrea (coords.), op. cit., p. 13. 
Esta revista forma parte del acervo de la Biblioteca Jurídica Virtual del Instituto de Investigaciones Jurídicas de la UNAM

De ahí que si se entiende el margen de apreciación nacional como objeto de un trasplante jurídico, éste no puede ser limitado al término, sino a la técnica de aplicación e interpretación, la cual puede equilibrarse en grados de ejercicio por parte de los Estados: teniendo en cuenta la naturaleza de las normas, el consenso nacional e internacional y su propia formulación, como, al parecer implícitamente, lo ha hecho el Sistema Interamericano. ${ }^{57}$

En el fondo, un análisis correlacional como se efectuó asiente que tanto la Corte como la Comisión han tenido la oportunidad de materializar la doctrina del margen de apreciación en algunas temáticas y a conceder categorías de discreción:

\section{TABLA 4. TEMÁTICAS QUE INCLUYEN ANÁLISIS DEL "MARGEN \\ DE APRECIACIÓN NACIONAL" EN EL SISTEMA INTERAMERICANO}

DE DERECHOS HUMANOS

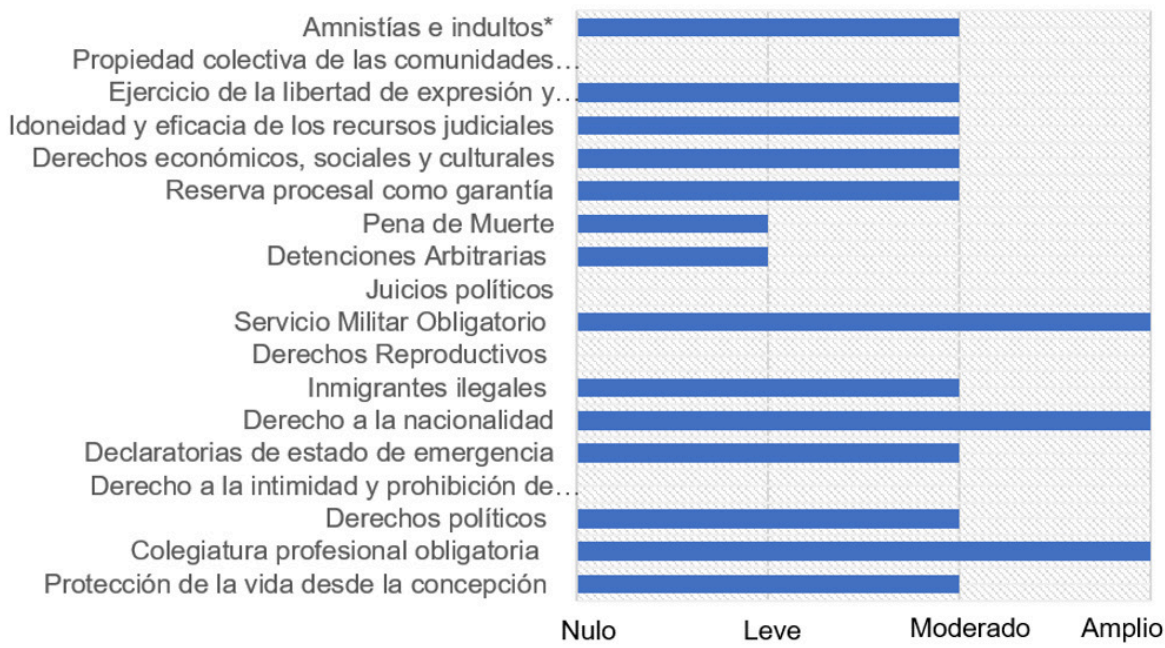

* Los Estados poseen nulo margen de apreciación respecto de amnistías e indultos por conductas de lesa humanidad.

Entendiéndose que dichas categorías de discreción interactúan con los niveles de control del siguiente modo:

57 Cfr. Henrard, Kristin, "A Critical Analysis of the Margin of Appreciation Doctrine of the ECtHR, with Special Attention to Rights of a Traditional Way of Life and a Healthy Environment: A Call for an Alternative Model of International Supervision”, The Yearbook of Polar Law, vol. IV, 2012, pp. 365-413. 


\section{TABla 5. Categorías Del “MARGEN DE APRECIACIÓN NACIONAL" Y MODALIDADES DE CONTROL}

\begin{tabular}{|c|c|c|c|c|}
\hline \multirow{4}{*}{ 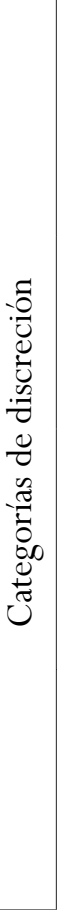 } & Nulo & $\begin{array}{l}\text { No existe posibilidad de aplicación del } \\
\text { margen de apreciación, al ser una norma } \\
\text { imperativa internacional carente de am- } \\
\text { bigüedad y sometida a un consenso inter- } \\
\text { nacional. }\end{array}$ & \multirow[t]{2}{*}{ Estricto } & \\
\hline & Leve & $\begin{array}{l}\text { Se enmarca en un ejercicio sometido a } \\
\text { límites imperativos que protegen el dere- } \\
\text { cho y cancelan la discrecionalidad injus- } \\
\text { tificada. }\end{array}$ & & \\
\hline & Moderado & $\begin{array}{l}\text { Se acciona de acuerdo a la normativa na- } \\
\text { cional, sin que ella pueda tocar o afectar } \\
\text { el núcleo fundamental del derecho o que } \\
\text { condicione el ejercicio de otros derechos } \\
\text { en su núcleo esencial. }\end{array}$ & Condicionado & \\
\hline & Amplio & $\begin{array}{l}\text { Se materializa el margen al no existir de- } \\
\text { terminación en la norma internacional } \\
\text { que ha sido ratificada, o existiendo, ésta } \\
\text { misma reconoce, directa o indirectamen- } \\
\text { te, la necesidad del consenso nacional. }\end{array}$ & Restringido & \\
\hline
\end{tabular}

Este modelo de comprensión de la doctrina del margen de apreciación obliga, de hecho, a que la supervisión de las obligaciones internacionales suponga un elemento de autorrestricción del Estado, primariamente, y que ésta se consolide como un proceso de elaboración social, so pena de que se llegue a perder de vista que la perdurabilidad del sistema internacional no puede ser un ejercicio de imposición, sino el camino de un acuerdo en lo fundamental.

VII. BIBLIOGRAFÍA

Acosta Alvarado, Paola Andrea, "Los casos colombianos ante el sistema interamericano y el uso del margen de apreciación: ¿ausencia justificada?”, en NúÑEz Poblete, Manuel y Acosta Alvarado, Paola Andrea 
(coords.), El margen de apreciación en el Sistema Interamericano de Derechos Humanos: proyecciones regionales y nacionales, México, UNAM, 2012.

ANRÒ, Ilaria, Il margine di apprezzamento nella giurisprudenza della Corte di giustizia dell'Unione europea e della Corte europea dei Diritti dell'uomo, Nápoles, Edizioni Scientifiche Italiane, 2010.

ARAI-TAKAHASHI, Yutaka, The Margin of Appreciation Doctrine and the Principle of Proportionality in the Jurisprudence of the ECHR, Antwerp, Intersentia, 2002 .

Astudillo, César, El bloque y el parámetro de constitucionalidad en México, México, Tirant lo Blanch, 2014.

BACKenkÖHler CASAJús, Christian J., "Transplante jurídico=Legal Trasplant”, Eunomía, núm. 17, octubre de 2019-marzo de 2020.

Balbontin Gallo, Cristóbal, "Volver a los orígenes: la soberanía, un concepto fundamental para comprender el derecho público", Revista Chilena de Derecho, vol. 45, núm. 3, septiembre-diciembre de 2018.

BARBOSA DELGADO, Francisco R., "El margen nacional de apreciación en el derecho internacional de los derechos humanos: entre el Estado de derecho y la sociedad democrática”, en NúÑEZ POBLETE, Manuel y ACOSTA Alvarado, Paola Andrea (coords.), El margen de apreciación en el Sistema Interamericano de Derechos Humanos: proyecciones regionales y nacionales, México, UNAM, 2012.

BARbosa Delgado, Francisco R., "Los límites a la doctrina del margen nacional de apreciación en el Tribunal Europeo y la Corte Interamericana de Derechos Humanos: intervención judicial en torno a ciertos derechos de las minorías étnicas y culturales”, Derecho del Estado, núm. 26, enero-junio de 2011.

Benavides Casals, María Angélica, "El Consenso Y El Margen De Apreciación En La Protección De Los Derechos”, Ius Et Praxis, vol. 15, núm. 1, enero-junio de 2009.

Bonilla Maldonado, Daniel (ed.), Teoría del derecho y trasplantes jurídicos, Bogotá, Siglo del Hombre y otros, 2009.

BURGORGUE-LARSEN, Laurence, "El contexto, las técnicas y las consecuencias de la interpretación de la Convención Americana de los Derechos Humanos", Estudios Constitucionales, vol. 12, núm. 1, enero-junio de 2014. Butler, Petra, "Margin of Appreciation. A Note Towards a Solution for the Pacific?", Victoria University of Wellington Law Review, vol. 39, núm. 4, diciembre de 2008. 
Cancela Outeda, Celso, El proceso de constitucionalización de la Unión Europea: "de Roma a Niza”, Santiago de Compostela, Universidad de Santiago de Compostela, 2001.

CÁRDENAS-CONTRERAS, Luz Eliyer, La evolución del margen de apreciación nacional en el Sistema Interamericano de Derechos Humanos como doctrina transregional, tesis de maestría en Derecho de Estado con énfasis en derecho público, Bogotá, Universidad Externado de Colombia, 2019.

ClÉRICO, Laura, "La enunciación del margen de apreciación: Fontevecchia 2017 desde los márgenes", Derechos en Acción, año, 3, vol. 7, núm. 7, otoño de 2018.

ClÉRICO, Laura y ALDAO, Martín, “Límites al margen de apreciación desde la perspectiva de género en intersección con pobreza”, Centro de Estudios Constitucionales, año IV, núm. 6, enero-junio de 2018.

CONTRERAS, Pablo, "Control de convencionalidad, deferencia internacional y discreción nacional en la jurisprudencia de la Corte Interamericana de Derechos Humanos", Ius et Praxis, año 20, núm. 2, julio-diciembre de 2014.

D’Alterio, Elisa, La funzione di regolazione delle Corti Nello Spaio Ammnistrativo Globale, Milano, Giuffrè, 2011.

FERnÁNDEZ PARRA, Sergio Alejandro, "El margen nacional de apreciación y el contenido de la libertad de pensamiento, conciencia y religión en el Convenio Europeo de Derechos Humanos”, Eunomía, núm. 17, octubre de 2019-marzo de 2020.

FUENTES-CONTRERAS, Édgar Hernán et al., "Facticidad y acción de tutela: presentación preliminar de un estudio empírico de la formulación y efectos de la acción de tutela en el marco colombiano, entre los años 1992-2011”, Civilizar, vol. 14, núm. 27, julio-diciembre de 2014.

FUENTES-CONTRERAS, Édgar Hernán, "Del Estado constitucional al Estado convencional de derecho. Estudio preliminar sobre el modelo del Estado convencional de derecho en el contexto latinoamericano", Revista Jurídica Digital UANDES, vol. 3, núm. 2, julio-diciembre de 2019.

FUENTES-CONTRERAS, Édgar Hernán, Legislación en sentido material, Bogotá, Grupo Editorial Ibáñez y otro, 2018.

Fuentes-Contreras, Édgar Hernán, Materialidad de la Constitución, Bogotá, Grupo Editorial Ibáñez y otro, 2010.

GARCÍA DE ENTERRÍA, Eduardo, "La lucha contra las inmunidades del poder en el derecho administrativo (poderes discrecionales, poderes de go- 
bierno, poderes normativos)”, Revista de Administración Pública, núm. 38, mayo-agosto de 1962.

GaRCía ROCA, Javier, El margen de apreciación nacional en la interpretación del Convenio Europeo de Derechos Humanos: soberanía e integración, Madrid, Civitas, 2010.

GaRCía ROCA, Javier, "La muy discrecional doctrina del margen de apreciación nacional según el Tribunal Europeo de Derechos Humanos: soberanía e integración”, Teoría y Realidad Constitucional, núm. 20, juliodiciembre de 2007.

GREER, Steven, The Margin of Appreciation: Interpretation and Discretion under the European Convention on Human Rights, Strasbourg, Council of Europe, 2000.

HENRARD, Kristin, "A Critical Analysis of the Margin of Appreciation Doctrine of the ECtHR, with Special Attention to Rights of a Traditional Way of Life and a Healthy Environment: A Call for an Alternative Model of International Supervision”, The Yearbook of Polar Law, vol. IV, 2012.

Hillgruber, Christian, "Soberanía. La defensa de un concepto jurídico", InDret, núm. 1, enero-marzo de 2009.

KRATOCHVíl, Jan, "The Inflation of the Margin of Appreciation by the European Court of Human Rights", Netherlands Quarterly of Human Rights, vol. 29, núm. 3, septiembre-noviembre de 2011.

LAISE, Luciano D., "La distinción entre interpretación y construcción: una visión crítica del originalismo del significado público", Ius et Praxis, vol. 25, núm. 3, diciembre de 2019.

LAISE, Luciano D., “¿Puede la expansión del derecho al acceso a la justicia potenciar al activismo judicial?", Anuario Iberoamericano de Justicia Constitucional, vol. 24, núm. 1, 2020.

LÓPEZ ALFONSín, Marcelo Alberto, "La doctrina del margen de apreciación nacional. Su recepción en el Sistema Europeo de Derechos Humanos, en el Sistema Interamericano de Derechos Humanos y en Argentina, en relación con los derechos económicos, sociales y culturales", Lex, año XV, núm. 19, enero-junio de 2017.

LóPez Hidalgo, Sebastián, Reflexiones acerca de la legitimidad democrática de la justicia constitucional en Ecuador, Quito, UASB, 2018.

LÓPEZ MedinA, Diego Eduardo, Teoría impura del derecho, Bogotá, Universidad de los Andes y otros, 2004. 
LOVATÓN PALACIOS, David, “¿Debería incorporarse en el Sistema Interamericano de Derechos Humanos la noción de margen de apreciación nacional?", Estudios Constitucionales, año 16, núm. 2, julio-diciembre de 2018.

Maldonado SÁnCHEZ, Adán, El bloque de constitucionalidad en México. Hacia su integración y aplicación, México, Tirant lo Blanch, 2019.

MAROCHINI, MAŠA, “The Interpretation of the European Convention on Human Rights”, Bornik Radova Pravnog Fakulteta u Splitu, vol. 51, núm. 1, enero-junio de 2014.

MARShall BARBERÁn, Pablo, "La soberanía popular como fundamento del orden estatal y como principio constitucional", Revista de Derecho, vol. 35, núm. 2, julio-diciembre de 2010.

MARTÍNEZ ESTAY, José Ignacio, “Auto-restricción, deferencia y margen de apreciación. Breve análisis de sus orígenes y de su desarrollo", Estudios Constitucionales, año 12, núm. 1, julio-diciembre de 2014.

MCGOLDRICK, Dominic, "A Defence of the Margin of Appreciation and an Argument for its Application by the Human Rights Committee", International and Comparative Law Quarterly, vol. 65, núm. 1, enero-marzo de 2016.

Mena ParRas, Francisco Javier, "Democracy, Diversity and the Margin of Appreciation: A Theoretical Analysis from the Perspective of the International and Constitutional Functions of the European Court of Human Rights”, REEI, núm. 29, julio-diciembre de 2015.

NASH ROJAS, Claudio, "La doctrina del margen de apreciación y su nula recepción en la jurisprudencia de la Corte Interamericana de Derechos Humanos", ACDI, vol. 11, 2008.

NúÑEZ Poblete, Manuel, "Sobre la doctrina del margen de apreciación nacional. La experiencia latinoamericana confrontada y el thelos constitucional de una técnica de adjudicación del derecho internacional de los derechos humanos", en Núñez Poblete, Manuel y Acosta Alvarado, Paola Andrea (coords.), El margen de apreciación en el Sistema Interamericano de Derechos Humanos: proyecciones regionales y nacionales, México, UNAM, 2012.

PASCUAL VIVES, Francisco José, "El margen de apreciación nacional en los tribunales regionales de derechos humanos: una aproximación consensualista”, Anuario Español de Derecho Internacional, vol. 29, 2013. 
Pereira Menaut, Antonio Carlos, “Después de la soberanía”, Revista de Derecho Político, núm. 50, enero-abril de 2001.

Pereira Menaut, Antonio Carlos, Doce tesis sobre la política, México, UNAM, 2008.

RodríGUEZ Villabona, Andrés Abel, "La interacción entre ordenamientos jurídicos: trasplante, recepción, adaptación e influencia en el derecho”, IUSTA, núm. 31, julio-diciembre de 2009.

SÁnCHEZ-Molina, Pablo, "El margen de apreciación nacional en las sentencias del Tribunal Europeo de Derechos Humanos relativas al derecho a elecciones libres", Estudios de Deusto, vol. 62, núm. 1, enero-junio de 2014.

SÁnChEZ Molina, Pablo, "Margen de apreciación nacional (en los sistemas de protección internacional de los derechos humanos)", Eunomía, núm. 9, octubre de 2015 -marzo de 2016.

Sommermann, Karl-Peter, "El papel de la ley alemana de la justicia administrativa para la realización del Estado de derecho", en ABERASTURI, Pedro (coord.), Ley de la justicia administrativa alemana, Buenos Aires, Konrad Adenauer-Abeledo Perrot, 2009.

Watson, Alan, Legal Transplants: An Approach to Comparative Law, Atenas y Londres, The University of Georgia Press, 1993. 